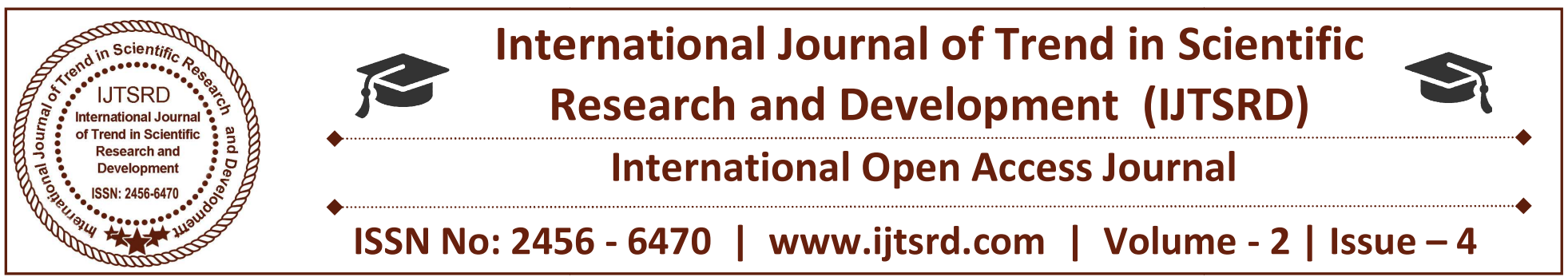

\title{
A Study on Environmental Responsibilities among Higher Secondary School Students
}

\author{
Ms. R. Geetharani ${ }^{1}$, Mr. K. Somasundaram ${ }^{2}$ \\ ${ }^{1} \mathrm{M}$. Ed Student, ${ }^{2}$ Assistant Professor \\ RVS College of Education, Coimbatore, Tamil Nadu, India
}

\section{ABSTRACT}

This research environmental

explores

values

interconnection between and environmental responsibility among young people. Basic question of this study was whether and to which degree the environmental values influence the development of the environmental responsibility? By answering on this question, we want to provide guidelines for educational activities in schools which aim to develop environmental awareness among the Tamil nadu school students. The survey covered a sample of 300 students from primary and secondary government schools from Coimbatore. Students were tested on a five point type scales which examined environmental responsibility and environmental values. To assess the reliability and validity of the scales standard statistical procedures were used. The results of our study confirmed positive linear dependence between environmental values and environmental responsibility. On the basis of students environmental values $48 \%$ of their environmental responsibility can be predicted On the basis of our results, it is possible to conclude that students who believe that efficient functioning of society and the survival of life on the Earth is unimaginable without environmental protection, display desirable attitudes towards environmental responsibility. The obtained results may help to identify future directions of formal education activities regarding the improvement of personal environmental responsibility among young people.

\section{INTRODUCTION}

Environmental responsibility forms one part of the broader concept of sustainable development. Sustainability refers to the notion of ensuring that economic growth and environmental protection work together in a long-term win-win situation, rather than operating in competition with each other. One of the most common definitions of sustainability is that put forward by the United Nations World Commission on Environment and Development. The Commission has described the idea of sustainable development as development which meets the needs of the present without compromising the ability of future generations to meet their own needs. The central theme in such a definition is the interdependence between economic growth and environmental quality, and the need to ensure that both issues are protected. Typically, sustainable development requires the balancing of three different but interrelated variables: economic and commercial imperatives to produce and maintain an economic system that delivers wealth and efficiently meets consumer needs; environmental considerations, so as to ensure that the current state of the earths biosphere is at least maintained and, wherever possible, enhanced; and social justice factors, or the protection of individual and community needs, on the assumption that the other two issues cannot be advanced if there is no motivation or incentive within the broader community to do so. The evolution of these issues over the last forty years can be traced through a number of pronounced stages The 1960s first saw the emergence of environmental concern as a major community issue, especially in the developing nations of Asia, North America and Australia. Governments began to respond to these concerns in the 1970s with an array of policy initiatives. These included the introduction of tighter, more prescriptive laws to protect the environment and limit the actions of business, the creation of 
specialized administrative bodies to deal with environmental concerns, and the appointment of environment ministries and departments at the state and national level. Initially, the business sector responded by largely opposing such developments. However, in the 1980s and 1990s an increasing number of senior managers and entrepreneurs began to accept the need to adopt a sustainable framework for business practices. Whilst most simply began to accept the legitimacy of environmental issues as a stake- holder influence, others began to propound the philosophy of market-based environmentalism. This perspective argued that being green could in fact be a source of innovation, competitive advantage, and new business generation, and claimed that the most effective way of protecting the environment was to provide an economic incentive for doing so.

As a result of these activities, today there is a wellestablished and rapidly growing body of research into the greening of business. Some of the academic business disciplines which have especially focused on this phenomenon include those of organizational change and development, tourism studies, economics and accounting. To date, however, most of the work dealing with these issues has been focused on large corporations, not on the small- and medium-sized industry sector. Whilst there is a small but growing number of researchers working in the SMEenvironment field the importance of small firms is usually overlooked. This is due to a number of reasons. Perhaps the first is that the impact of larger firms on the environment tends to be more noticeable. As a result, it is easier to see, mea- sure, understand and evaluate the impact of such large firms. In addition, larger firms tend to have more experience in dealing with multiple stake- holder pressures, and have become adept at handling the need for a greener business perspective. A second reason is the nature and structure of the SME sector. Most small firms are, by definition, relatively mini scale, as is their environmental im- pact. Their individual levels of waste and energy usage, for example, are extremely small. Moreover, many firms (especially in the wealthy developed economies) tend to be located within the services sector, and so have no obvious dirty industrial practices. Hence, they appear to have lit- tle, or no, environmental impact.

\section{REVIEW OF LITERATURE}

Lee, J. W., Kim, Y. M., \& Kim, Y. E. (2018): Examined the antecedents of organizational commitment for adopting corporate environmental responsibility and green practices in the case of the logistics industry in South Korea. Seven hundred and eighty employees and top management from logistics companies were sampled. The data were analyzed using factor analysis, structural equation modeling techniques, and one-way analysis of variance. The results showed that social expectations, organizational support, and stakeholder pressure were the important antecedents for the adoption of corporate environmental responsibility and green practices. In the path analysis, social expectations had the greatest impact on both stakeholder pressure and green practice adoption. Moreover, we found that the higher the job titles were, the more willing they were to adopt green practices. This indicated that the current top management of Korean logistics companies is well aware of being mandated to make a commitment to corporate environmental responsibility and green practices.

Zimmerman, H. T., \& Weible, J. L. (2017): collected the Guided by sociocultural perspectives on the importance of place as a resource for learning, we investigated 14- and 15-year old students understandings of their community and water quality during a school-based watershed unit. Methods included a theory-driven thematic analysis of field notes and video transcripts from four biology classrooms, a qualitative and quantitative analysis of 67 pairs of matched pre- and post intervention mind maps, and a content analysis of 73 student reflections. As they learned about water quality, learners recognized the relevance of the watersheds health to the health of their community. Students acknowledged the im- pacts of local economically driven activities (e.g., natural gas wells, application of agrichemicals) and leisure activities (e.g., boating, fishing) on the watersheds environmental health. As students learned in and about their watershed, they experienced both connections and tensions between their everyday experiences and the environmental problems in their community. The students suggested individual sustainability actions needed to address water quality issues; however, the stu- dents struggled to understand how to act collectively. Implications of rural experiences as assets to future environmental sciences learning are discussed as well as the implications of educational experiences that do not 
include an advocacy component when students uncover environmental health issues. We suggest further consideration is needed Guided by sociocultural perspectives on the importance of place as a resource for learning, we investigated 14- and 15year old students understandings of their community and water quality during a school-based watershed unit. Methods included a theory-driven thematic analysis of field notes and video transcripts from four biology classrooms, a qualitative and quantitative analysis of 67 pairs of matched pre- and post intervention mind maps, and a content analysis of 73 student reflections. As they learned about water quality, learners recognized the relevance of the watersheds health to the health of their community. Students acknowledged the impacts of local economically driven activities (e.g., natural gas wells, application of agrochemicals) and leisure activities (e.g., boating, fishing) on the watersheds environmental health. As students learned in and about their watershed, they experienced both connections and tensions between their everyday experiences and the environmental problems in their community. The students suggested individual sustainability actions needed to address water quality issues; however, the students struggled to understand how to act collectively. Implications of rural experiences as assets to future environmental sciences learning are discussed as well as the implications of educational experiences that do not include an advocacy component when students uncover environmental health issues. We suggest further consideration is needed.

Helker, K., \& Wosnitza, M. (2016): explained Due to the important motivational implications of an individuals sense of responsibility, this paper studies the interplay of 271 secondary school students and 101 of their parents responsibility ascriptions for student learning and their relations to student motivation and achievement. Three dimensions of responsibility were identified; responsibility for the learning process, student achievement and establishing a supportive social network. Students sense of personal responsibility was related to their ascriptions of responsibility to parents and teachers and their own subject-specific motivation and school achievement. All of these were found related to parents responsibility judgements and expectancies. These findings underscore the importance of the school context for fostering students, teachers and parents sense of responsibility for ensuring students academic success. Attaran, S., \& Celik, B. G. (2015): Proposed the purpose of this study is to explore environmental attitudes and how such attitudes, when combined with a specific cost, can affect environmental behavior. Environmental attitudes are important to study due to the rising belief by building occupants that they are owed safe, healthy, environmentally responsible, and comfortable living environments. Universities around the world are responding to such demands as the majority of prospective college students and their parents claim that the environmental record is a determining factor in their selection of a university. Therefore, this study examines the environmental responsibility levels of a sample student population and to explore how these scores, along with gender, impact their willingness to pay for studying and living in green buildings. Dgl, C., \& Holtbrgge, D. (2014): proposed Employer reputation is relevant not only to attract but also to retain qualified employees. While in the past financial incentives have been the most important instrument, corporate environmental responsibility (CER) is becoming more and more relevant as a determinant for I employer attractiveness and employee commitment. On the basis of signaling theory, we conducted an empirical study among 215 firms in China, Germany, India and the USA. Our results reveal that green strategy \& culture, green technology $\&$ products, green recruitment \& evaluation and green communication positively influence the environmental reputation of a company as an employer and in turn employee commitment. The signaling effects of these CER activities are similar in Germany and the USA (developed economies) as well as in China and India (emerging economies). An exception is green communication, which has a more positive effect on environmental reputation in developed economies. We conclude with managerial and theoretical implications as well as recommendations for future research. Nejati, M., \& Nejati, M. (2013) discussed Given the growing global interest on the universitys role towards promoting sustainability, an increasing number of universities are committing themselves to sustainability. Nonetheless, many of university stakeholders and academicians are unaware of sustainability principles. In the lack of sufficient studies to investigate the perceptions of major stakeholders within the university setting on the role of the university in contributing to sustainability, the current study aims to investigate the perceptions of university students towards factors of a sustainable university by 
developing a reliable scale to assess sustainability practices of universities. Through examining the perception of 379 university students, a standard scale design process was applied. Upon validation of the proposed scale, a four-dimensional structure for the key factors of a sustainable university from the perspective of students was identified, including 1) community outreach, 2) sustainability commitment and monitoring, 3) waste and energy, and 4) land use and planning. Finally, implications were discussed. McNeill, K. L., \& Vaughn, M. H. (2012): investigated how the enactment of a climate change curriculum supports students development of critical science agency, which includes students developing deep understandings of science concepts and the ability to take action at the individual and community levels. We examined the impact of a four to six week urban ecology curriculum on students from three different urban high schools in the USA. Data collection included pre and posttest written assessments from all students $(n=75)$ and pre and post interviews from focal students $(n=22)$ to examine how students conceptual understandings, beliefs and environmental actions changed. Our analyses showed that at the beginning of the curriculum, the majority of students believed that climate change was occurring; yet, they had limited conceptual understandings about climate change and were engaged in limited environmental actions.

\section{OBJECTIVES OF THE STUDY}

1. To study the awareness of environmental responsibilities among higher secondary school students.

2. To develop a questionnaire to assess the awareness of environmental responsibilities among higher secondary school students.

3. To find out the level of environmental responsibility and its dimensions among the higher secondary students with respect to their gender.

4. To find out the level of environmental responsibility and its dimensions among the higher secondary students with respect to their religion.

5. To find out the level of environmental responsibility and its dimensions among the higher secondary students with respect to their locality of students.

6. To find out the level of environmental responsibility and its dimensions among the higher secondary students with respect to their nature of school.

7. To find out the level of environmental responsibility and its dimensions among the higher secondary students with respect to their fathers occupation.

8. To find out the level of environmental responsibility and its dimensions among the higher secondary students with respect to their medium instruction.

\section{RESEARCH QUESTIONS}

1. Is there any significance mean score difference between gender and awareness of environmental responsibilities among higher secondary school students?

2. Is there any significance mean score difference between Locality and awareness of environmental responsibilities among higher secondary school students?

3. Is there any significance mean score difference between Type of school and awareness of environmental responsibilities among higher secondary school students?

4. Is there any significance mean score difference between Medium instruction and awareness of environmental responsibilities among higher secondary school students?

5. Is there any significance mean score difference between Parents occupation and awareness of environmental responsibilities among higher secondary school students?

\section{HYPOTHESES}

1. There will be a significant difference between male and female of higher secondary school students in environmental responsibility and its dimensions.

2. There will be a significant difference among higher secondary school students in environmental responsibility with respect to their Religion.

3. There will be a significant difference among higher secondary school students in environmental responsibility with respect to their Locality.

4. There will be a significant difference among higher secondary school students in environmental responsibility with respect to their Type of school.

5. There will be a significant difference among higher secondary school students in environmental responsibility with respect to their Parents occupation. 
6. There will be a significant difference among higher secondary school students in environmental responsibility with respect to their Medium instruction.

\section{VARIABLES}

An independent variable is a variable that is expected to influence the dependent variables.Its value may be changed or altered, which is inde- pendent of any other variables.Also the following demographic variables were used as independent variables.

$>$ Gender (Male/Female).

$>$ Locality (Rural/Urban).

$>$ Type of school (Government/Private).

$>$ Medium instruction (Tamil/English).

$>$ Parents occupation (Government/Private).

Dependent variable are those events which are by hypothesized as dependent on the changes in the dependent variable (Awareness of environmental responsibilities among higher secondary school students).

\section{DESIGN OF THE STUDY}

In the presence study Normative survey method will be adopted. Survey research employee questioner and interview to our people who pro- vide informations about them selfs their attitude and believes demographic (Age, Gender, Income and So on) the survey method can be classified into many, but according to the objectives and hypotheses in this presence study normative survey method will be adopted.

\section{POPULATION AND SAMPLE}

Coimbatore district is one of the district in Tamilnadu, India. Coimbatore is finest education district of Tamilnadu. It is the second largest city in Tamilnadu and one of the fastest growing cities in Tamilnadu State. For the present study the investigator select only 6 Schools from both Government and Private School around Coimbatore. Investigator selected Datas will be collected from the samples of 300 Students of various schools.

\section{SAMPLING TECHNIQUES}

Sampling procedure is a definite plan determined before any data are actually collected for obtaining a sample from a given population under the simple random sampling technique. This sampling method is used for selecting samples. Simple random sampling is method in which each and every element in the population has an equal chance of getting selected. The study is based on primary data which is collected from 300 school students at higher secondary level and around Coimbatore district. The sample which was collected from various college located in and around Coimbatore is shown as below.

Table 1.1 List of schools used for data collection

\begin{tabular}{|l|l|l|}
\hline \multicolumn{1}{|c|}{ S. } & \multicolumn{1}{|c|}{ Name of the schools } & \multicolumn{1}{|c|}{$\begin{array}{c}\text { Number } \\
\text { of } \\
\text { students }\end{array}$} \\
\hline 1. & $\begin{array}{l}\text { Govt. Boys. Hr. Sec. School, } \\
\text { Udumalpet }\end{array}$ & 52 \\
\hline 2. & $\begin{array}{l}\text { Govt. Girls. Hr. Sec. School, } \\
\text { Udumalpet }\end{array}$ & 56 \\
\hline 3. & $\begin{array}{l}\text { Govt. Hr. Sec. School, } \\
\text { Pethappampatti }\end{array}$ & 47 \\
\hline 4. & $\begin{array}{l}\text { Sri Visalakshi Girls Higher } \\
\text { Secondary School, Udumalpet }\end{array}$ & 49 \\
\hline 5. & $\begin{array}{l}\text { Oxford Matric Hr. Sec. School, } \\
\text { Kongal-Nagaram }\end{array}$ & 52 \\
\hline 6. & R. G. M. Hss Udumalpet & 56 \\
\hline
\end{tabular}

TABLE 1.2

Distribution of samples based on variables

\begin{tabular}{|c|c|c|c|c|}
\hline Category & Subgroups & Number & $\%$ & Total \\
\hline \multirow{2}{*}{ Gender } & Male & 159 & 53 & \multirow{2}{*}{300} \\
\cline { 2 - 4 } & Female & 141 & 47 & \\
\hline Locality & Rural & 222 & 74 & \multirow{2}{*}{300} \\
\cline { 2 - 4 } & English & 78 & 26 & \\
\hline \multirow{2}{*}{$\begin{array}{c}\text { School } \\
\text { Type }\end{array}$} & Government & 147 & 49 & \multirow{2}{*}{300} \\
\cline { 2 - 4 } $\begin{array}{c}\text { Medium } \\
\text { instruction }\end{array}$ & Private & 153 & 51 & \\
\hline Parents & Tamil & 203 & 73 & \multirow{2}{*}{300} \\
\cline { 2 - 4 } occupation & Government & 66 & 22 & \multirow{2}{*}{300} \\
\cline { 2 - 4 } & Private & 234 & 78 & \\
\hline
\end{tabular}

\section{RESEARCH TOOL}

Tool become another major consideration in an education research. The instrument employed for the collection of data required for the study of any problem is called tool. Tool employ distinction way of describing and qualifying the data the important tools of educational research include inter- view schedule, questionnaire, observation, rating scale, proficiency test, psychological tests and sociogram.

\section{TESTING HYPOTHESIS 1:}

There will be a significant mean score difference in awareness of environmental responsibilities among 
higher secondary school students based on gender (Male/Female).

TABLE 1.3

Mean Score difference and $t$ - value of factors related to awareness of environmental responsibilities among higher secondary school students based on gender

\begin{tabular}{|c|c|c|c|c|c|c|}
\hline $\begin{array}{c}\text { S. } \\
\text { No. }\end{array}$ & Gender & N & Mean & Df & $\begin{array}{c}\text { T- } \\
\text { Value }\end{array}$ & Result \\
\cline { 1 - 4 } 1 & Male & 159 & 1.3813 & 299 & 2.056 & S \\
\cline { 1 - 4 } 2 & Female & 141 & 1.2618 & & & \\
\hline \multicolumn{2}{|c|}{ Total } & 300 & 1.3216 & & & \\
\hline
\end{tabular}

The Table 1.3 shows the mean score difference in awareness of environmental responsibilities among higher secondary school students based on gender (Male/Female). The calculate $\mathrm{t}$ value is statistically a significance at 0.05 levels and hence the hypotheses 1 is accepted. It can be concluded that there is - a significant difference in mean score difference in awareness of environmental responsibilities among higher secondary school students based on gender.

Female : 1.2618

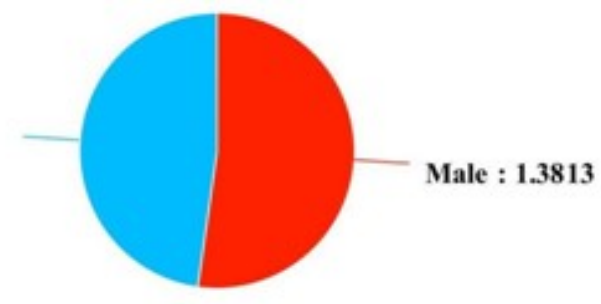

Figure 1: Relationship between Students Gender and Awareness of Environmental Responsibilities among Higher Secondary School Students

\section{TESTING HYPOTHESIS 2:}

There will be a significant mean score difference in awareness of environmental responsibilities among higher secondary school students based on Locality (Rural/Urban).

\section{TABLE 1.4}

Mean Score difference and t- value of factors related to awareness of environmental responsibilities among higher secondary school students based on Locality (Rural/Urban).

\begin{tabular}{|c|l|c|c|c|c|c|}
\hline $\begin{array}{c}\text { S. } \\
\text { No. }\end{array}$ & $\begin{array}{c}\text { Localit } \\
\mathrm{y}\end{array}$ & $\mathrm{N}$ & Mean & Df & $\begin{array}{c}\text { T- } \\
\text { Value }\end{array}$ & Result \\
\cline { 1 - 4 } 1 & Rural & 222 & 1.2567 & & - & \\
\cline { 1 - 4 } 2 & Urban & 78 & 1.3456 & 299 & 2.678 & $\mathrm{~S}$ \\
\cline { 1 - 4 } & Total & 300 & 1.3012 & & & \\
\hline
\end{tabular}

The Table 1.4 shows the mean score difference in awareness of environmental responsibilities among higher secondary school students based on Locality (Rural/Urban). The calculate $\mathrm{t}$ value is statistically a significance at 0.05 levels and hence the hypotheses 2 is accepted. It can be concluded that there is a significant difference in mean score difference in awareness of environmental responsibilities among higher secondary school students based on Locality.

Rural : 1.2567

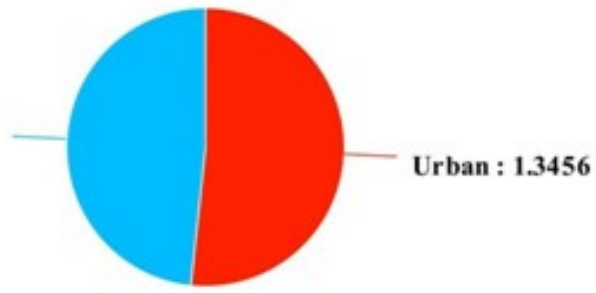

Figure 2: Relationship between Locality and Awareness of Environmental Responsibilities among Higher Secondary School Students

\section{TESTING HYPOTHESIS 3:}

There will be a significant mean score difference in awareness of environmental responsibilities among higher secondary school students based on Type of school (Government/Private).

TABLE 1.5

Mean Score difference and t- value of factors related to awareness of environmental responsibilities among higher secondary school students based on Type of school (Government/Private)

\begin{tabular}{|c|c|c|c|c|c|c|}
\hline $\begin{array}{c}\text { S. } \\
\text { No. }\end{array}$ & $\begin{array}{l}\text { School } \\
\text { type }\end{array}$ & N & Mean & Df & $\begin{array}{c}\text { T- } \\
\text { Value }\end{array}$ & Result \\
\cline { 1 - 4 } 1 & $\begin{array}{l}\text { Gover } \\
\text { nment }\end{array}$ & 147 & 1.2098 & \multirow{2}{*}{299} & 2.016 & $\mathrm{~S}$ \\
\cline { 1 - 4 } 2 & Private & 153 & 1.3451 & & \\
\cline { 1 - 3 } & Total & 300 & 1.2775 & & \\
\hline
\end{tabular}

The Table 1.5 shows the mean score difference in awareness of environmental responsibilities among higher secondary school students based on Type of school (Government/Private). The calcu- late $t$ value is statistically a significance at 0.05 levels and hence the hypotheses 3 is accepted. It can be concluded that there is a significant dif- ference in mean score difference in awareness of environmental responsibilities among higher sec- ondary school students based on Type of school (Government/Private). 
Government : $\mathbf{1 . 2 0 9 8}$

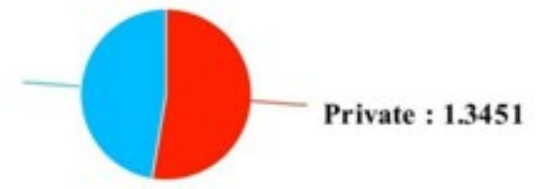

Figure 3: Relationship between Students school type and Awareness of Environmental Responsibilities

among Higher Secondary School Students

\section{TESTING HYPOTHESIS 4:}

There will be a significant mean score difference in awareness of environmental responsibilities among higher secondary school students based on Medium instruction (Tamil/English).

\section{TABLE 1.6}

Mean Score difference and t- value of factors related to awareness of environmental responsibilities among higher secondary school students based on Medium instruction (Tamil/English).

\begin{tabular}{|l|l|l|l|l|l|l|}
\hline $\begin{array}{l}\text { S. } \\
\text { No. }\end{array}$ & $\begin{array}{l}\text { Mediu } \\
\text { m }\end{array}$ & N & Mean & Df & $\begin{array}{l}\text { T- } \\
\text { Value }\end{array}$ & Result \\
\hline 1 & Tamil & 203 & 1.3457 & & & \\
\cline { 1 - 5 } 2 & English & 97 & 1.4315 & 299 & $\begin{array}{l}0 . \text { ter } \\
8912\end{array}$ & NS IO \\
\hline \multicolumn{2}{|l|}{ Total } & 300 & 1.3886 & & 8912 & \\
\hline
\end{tabular}

The Table 1.6 shows the mean score difference in awareness of environmental responsibilities among higher secondary school students based on Medium instruction (Tamil/English).The calculate $t$ value is statistically no significance at 0.05 levels and hence the hypotheses 4 is rejected. It can be concluded that there is no significant in awareness of environmental responsibilities among higher secondary school students based on Medium instruction (Tamil/English).

English : 1.4315

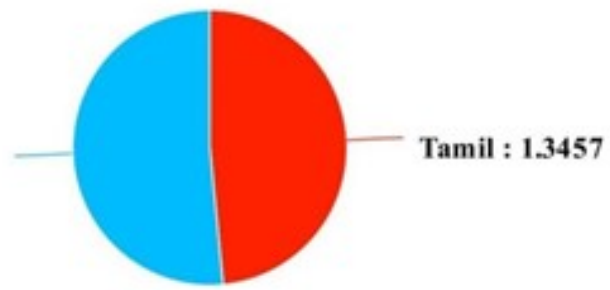

Figure4.3: Relationship between Students medium of instruction and Awareness of Environmental Responsibilities among Higher Secondary School Students

\section{TESTING HYPOTHESIS 5:}

There will be a significant mean score difference in awareness of environmental responsibilities among higher secondary school students based on Parents occupation (Government/Private).

\section{TABLE 1.7}

Mean Score difference and t- value of factors related to awareness of environmental responsibilities among higher secondary school students based on Parents occupation (Government/Private).

\begin{tabular}{|c|c|c|c|c|c|c|}
\hline $\begin{array}{c}\text { S. } \\
\text { No. }\end{array}$ & $\begin{array}{c}\text { Parent } \\
\text { Occup } \\
\text { ation }\end{array}$ & N & Mean & Df & $\begin{array}{c}\text { T- } \\
\text { Value }\end{array}$ & Result \\
\cline { 1 - 4 } 1 & $\begin{array}{l}\text { Gover } \\
\text { nment }\end{array}$ & 66 & 1.0989 & \multirow{2}{*}{299} & 0.7891 & NS \\
\cline { 1 - 4 } 2 & Private & 234 & 1.3987 & & \\
\cline { 1 - 4 } & Total & 300 & 1.2488 & & \\
\hline
\end{tabular}

The Table 1.7shows the mean score difference in awareness of environmental responsibilities among higher secondary school students based on Parents occupation (Government/Private). The calculate $t$ value is statistically no significance at 0.05 levels and hence the hypotheses 4 is rejected. It can be concluded that there is no significant in awareness of environmental responsibilities among higher secondary tils school students based on Parents occupation (Government/Private).

Private : 1.3987

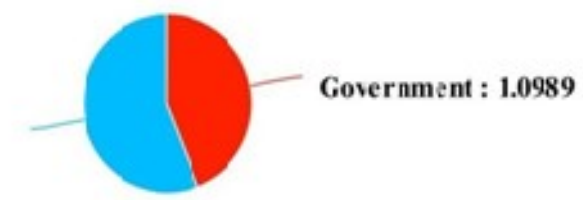

Figure4.3: Relationship between Students medium of instruction and Awareness of Environmental

Responsibilities among Higher Secondary School Students

\section{FINDINGS OF THE STUDY}

$>$ There is a significant relationship between gender and awareness of environmental responsibilities among higher secondary school students.

$>$ There is a significant relationship between Locality related factors and awareness of environmental responsibilities among higher secondary school students.

$>$ There is a significant relationship between Type of school and awareness of environmental responsibilities among higher secondary school students.

There is no significant relationship between Medium instruction and awareness of environ- 
mental responsibilities among higher secondary school students.

$>$ There is no significant relationship between Parents occupation and awareness of environmental responsibilities among higher secondary school students.

\section{SUMMARY}

$>$ A study of awareness of environmental responsibilities among higher secondary school students was studied and the findings reveal that there is a significant difference between awareness of environmental responsibilities among higher secondary school students with respect to gender, Locality and Type of school.

$>$ A study of awareness of environmental responsibilities among higher secondary school students was studied and the findings reveal that there is no significant difference between awareness of environmental responsibilities among higher secondary school students with respect to Parents occupation and Medium instruction.

\section{LIMITATIONS}

$>$ The study has certain limitation, which are as follows:

$>$ Only 300 students are selected as sampling for the study.

$>$ The project has been restricted to analyze and studyin awareness of environmental responsibilities among higher secondary school students.

$>$ The study is restricted to the school students of Coimbatore.

\section{CONCLUSION}

AND

FUTURE

\section{RECOMMENDATIONS}

$>$ A Similar Study can be conducted for dissertation by taking more number of concepts and students.

$>$ The study can be conducted to other schools around Tamilnadu.

$>$ Present survey helps to investigate the in awareness of environmental responsibilities among higher secondary school students.

The conclusion is that there is a significant relationship between gender, Locality, Type of school and fathers occupation on awareness of environmental responsibilities among higher secondary school students. While taking decision on awareness of environmental responsibilities among higher secondary school students their Locality, Type of school and fathers occupation has to be taken for decision making process.

\section{BIBLIOGRAPHY}

1. Aithal, P. S., Shailashree, V. T., \& Kumar, P. M. (2016). Analysis of NAAC Accreditation System using ABCD framework.

2. Ali, R., \& Sinha, B. (2013). A study of environmental awareness and ecological behaviouramong female B. Ed. students. An International Refereed E Journal, 2(1), 41-50.

3. Annunziata, E., Testa, F., Iraldo, F., \& Frey, M. (2016). Environmental responsibility in building design: an Italian regional study. Journal of Cleaner Production, 112, 639-648.

4. Attaran, S., \& Celik, B. G. (2015). Students environmental responsibility and their willingness to pay for green buildings. International Journal of Sustainability in Higher Education, 16(3), 327340.

5. Carnero, M. C. (2018). Model for assessment of environmental responsibility in health care organizations. In Encyclopedia of Information Science and Technology, Fourth Edition (pp. 3131-3143). IGI Global.

6. Chopra, A., \& Marriya, S. (2014). Corporate social responsibility and education in India.

7. Choudri, B. S., Baawain, M., Al-Zeidi, K., AlNofli, H., Al-Busaidi, R., \& Al-Fazari, K. (2017). Citizen perception on environmental responsibility of the corporate sector in rural areas. Environment, Development and Sustainability, 19(6), 2565-2576.

8. Efstathiou, Irene, Eleni A. Kyza, and Yiannis Georgiou.(2018): An inquiry-based augmented reality mobile learning approach to fostering primary school students historical reasoning in non-formal settings. Interactive Learning Environments 26.1 22-41.

9. Huang, Chester SJ, et al. (2016): Effects of situated mobile learning approach on learning motivation and performance of EFL students. Journal of Educational Technology \& Society 19.1263.

10. Huang, YuehMin, and PoSheng Chiu. (2015): The effectiveness of a meaningful learningbased evaluation model for context aware mobile 
learning. British Journal of Educational Technology 46.2 437-447.

11. Kalloo, Vani, and Permanand Mohan.(2013): An investigation into mobile learning for high school mathematics. Innovations in mobile educational technologies and applications 301-317.

12. Karthikeyan, P., K. V. Uma, and S. Pudumalar.(2015):Effectiveness of Mobile Learning at TCE, India: A Learner Perspective. Technology for Education (T4E), IEEE Seventh International Conference on. IEEE, 2015.

13. Kattayat, Sandhya, Smitha Josey, and J. V. Asha.(2017): Mobile learning apps in instruction and students achievement. International Journal of Interactive Mobile Technologies (iJIM) 11.1 143147.

14. Kim, Yanghee, and Diantha Smith.(2017): Pedagogical and technological augmentation of mobile learning for young children interactive learning environments. Interactive Learning Environments 25.14-16.

15. Krishna, P. Venkata, et al.(2016): Learning automata based decision making algorithm for task offloading in mobile cloud. Computer, Information and Telecommunication Systems (CITS), International Conference on. IEEE, 2016.

16. Krishnan, Kalyani, Reshmy Krishnan, and Ayyakannu Muthumari. (2017): A semantic based ontology mapping information retrieval for mobile learning resources. International Journal of Computers and Applications 39.3 169-178.

17. Negev, M., Sagy, G., Garb, Y., Salzberg, A., \&Tal, A. (2008). Evaluating the environmental literacy of Israeli elementary and high school students. The Journal of Environmental Education, 39(2), 3-20.

18. Nejati, M.,\&Nejati, M. (2013). Assessment of sustainable university factors from the perspective of university students. Journal of Cleaner Production, 48, 101-107.

19. Noordin, T. A.,\&Sulaiman, S. (2010). The status on the level of environmental awareness in the concept of sustainable development amongst secondary school students. ProcediaSocial and Behavioral Sciences, 2(2), 1276-1280.

20. Ramadoss, A., \& Poyyamoli, G. (2010). Biodiversity conservation through environmental education for sustainable development-a case study from puducherry, India. International Electronic Journal of Environmental Education, 1(2).

21. Ruia, A., Gupta, R. K., \& Bandyopadhyay, G. (2018). Can Corporate Social Responsibility be a Force Multiplier to Control Malnutrition in India?. Indian Journal of Public Health Research \& Development, 9(2).

22. Uitto, A., Juuti, K., Lavonen, J., Byman, R., \& Meisalo, V. (2011). Secondary school students interests, attitudes and values concerning school science related to environmental issues in Finland. Environmental education research, 17(2), $167-186$.

23. Zimmerman, H. T., \& Weible, J. L. (2017). Learning in and about rural places: Connections and tensions between students everyday experiences and environmental quality issues in their community. Cultural Studies of Science Education, 12(1), 7-31.

\section{APPENDICESPROFORMA FOR BASIC DATA}

1. Name of the student:

2. Name of the School:

3. Gender : Male [] Female []

4. Students Locality : Rural [] Urban []

5. Type of school : Government[] Private[ ]

6. Medium instruction : Tamil[ ] English[]

7. Fathers Occupation : Government[] Private[ ] 
International Journal of Trend in Scientific Research and Development (IJTSRD) ISSN: 2456-6470

\section{QUESTIONNAIRE}

\begin{tabular}{|c|c|c|c|c|c|c|}
\hline $\begin{array}{l}\text { S. } \\
\text { No. }\end{array}$ & Question & A & SA & $\mathbf{N}$ & DG & SDG \\
\hline 1 & $\begin{array}{l}\text { I feel personally responsible for helping to solve environmental } \\
\text { problems. }\end{array}$ & & & & & \\
\hline 2 & People are responsible for any damages they cause to the environments. & & & & & \\
\hline 3 & All plants and animal play an important role in the environment. & & & & & \\
\hline 4 & Usage of plastic bags should be restricted. & & & & & \\
\hline 5 & Smokes from vehicles, factories, crackers etc creates air pollution. & & & & & \\
\hline 6 & $\begin{array}{l}\text { Using bicycles instead of motor cycles is a way to protect an } \\
\text { environment. }\end{array}$ & & & & & \\
\hline 7 & Laws regarding water quality should be strict. & & & & & \\
\hline 8 & We can use cloth bags or jute bags instead of polythene bags. & & & & & \\
\hline 9 & Plants and animals have as much right as human to exist. & & & & & \\
\hline 10 & Drinking of polluted water cause cholera, diarrhea. & & & & & \\
\hline 11 & Technological changes often do as much harm to the environment. & & & & & \\
\hline 12 & To increase ground water we can recycle waste water. & & & & & \\
\hline 13 & By providing safety measures we can balance existing animals. & & & & & \\
\hline 14 & I prepare to bye green product. & A & & & & \\
\hline 15 & I would like to plant more trees. & 8 & & & & \\
\hline 16 & We should drink only purified drinking water. & & 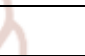 & & & \\
\hline 17 & We are frequently disturbed of noise pollution. & & & & & \\
\hline 18 & The usage of pesticides in food production should be strictly prohibited. & & & & & \\
\hline 19 & Depletion of ozone layer causes skin cancer. in Scientific & & & & & \\
\hline 20 & Depletion of ozone layer results in global warming. & & & & & \\
\hline 21 & Use a bucket of water instead of showers to take bath. & $=$ & & & & \\
\hline 22 & Do not let the tap run while you brush your Teeth & - & & & & \\
\hline 23 & Plants keep air fresh and clean. & & 4 & & & \\
\hline 24 & $\begin{array}{l}\text { The extensive use of chlorofluorocarbons in refrigeration earlier has } \\
\text { depleted the ozone layer to the great extent. }\end{array}$ & & & & & \\
\hline 25 & We should plant more trees than we cut down to keep our earth green. & 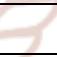 & & & & \\
\hline 26 & Use both sides of every piece of paper. & 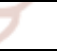 & & & & \\
\hline 27 & Deforestation harms our environment. & & & & & \\
\hline 28 & Plant more trees to get pure air, rain and to prevent soil erosion. & & & & & \\
\hline 29 & $\begin{array}{l}\text { Release of chemical wastes from factories in the water bodies harms our } \\
\text { environment. }\end{array}$ & & & & & \\
\hline 30 & It is important that everyone be aware of en- vironmental problems. & & & & & \\
\hline 31 & Establishing sanctuaries will protect wild animals. & & & & & \\
\hline 32 & Rain water preservation increases ground water. & & & & & \\
\hline
\end{tabular}

A -Agree

SA -Strongly Agree

N -No Idea

DG -Disagree

SDG -Strongly disagree 